\title{
SOCIAL SUPPORT IN GROUPS OF MOTHERS WITH DIFFERENT FAMILY STATUS AND ITS SIGNIFICANCE FOR SATISFACTION WITH WORK
}

\author{
${ }^{1}$ Jan Długosz University in Częstochowa, Częstochowa, Poland \\ Faculty of Philology and History, Department of Psychology \\ ${ }^{2}$ Kazimierz Wielki University in Bydgoszcz, Bydgoszcz, Poland \\ Faculty of Pedagogy and Psychology, Institute of Psychology, Department of Psychopathology and Clinical Diagnosis
}

\begin{abstract}
Background: The purpose of the study was to determine to what degree social support is differentiated by family situation, with consideration of single motherhood as a difficult circumstance, and to establish if social support is significant for satisfaction with work in the studied group of mothers. Material and Methods: The sample consisted of 421 mothers: 206 (49\%) of them were in a formal or casual relationship, and the remaining 215 (51\%) were single mothers. The sample was studied by means of the Berlin Social Support Scales (BSSS), and the Scale of Satisfaction with Work. Results: The results showed that single mothers perceived and obtained significantly less social support than mothers in relationships, and they offered to their relatives much more protective support $(\mathrm{p}=0.006)$. Satisfaction with work among mothers - regardless of the family status - grows if the mother receives more social support. The information support received by mothers in relationships is not significantly related to satisfaction with work; seeking that type of support by single mothers does not have a meaningful relationship with satisfaction with work, either. Moreover, regardless of the mothers' family status, satisfaction with work is significantly differentiated by each type of social support, except for protective support. Conclusions: Social support is differentiated by the mothers' situation in the family and at work, and it has a different impact on single mothers from the impact on mothers in relationships. Med Pr 2018;69(5):497-507
\end{abstract}

Key words: social support, job satisfaction, work satisfaction, single mothers, single motherhood, mothers from full family

Corresponding author: Elżbieta Napora, Jan Długosz University in Częstochowa, Faculty of Philology and History, Department of Psychology, Zbierskiego 2/4, 42-200 Częstochowa, Poland, email: elnapora@poczta.onet.pl

Received: September 8, 2017, accepted: April 12, 2018

\section{INTRODUCTION}

\section{Satisfaction with work}

Satisfaction with work is defined as an emotional reaction of pleasure or discontent experienced in connection with performing certain tasks, functions, and roles [1]. The level of satisfaction with work is expressed in an individual's attitude towards it and in opinions on the tasks performed at work [2]. The level of satisfaction with work depends on subjective factors and those related to the working environment [3]. Differences in perception and assessment of the factors constituting satisfaction with work are caused by individual and situational differences, such as type of family environment, the number of children, and interaction between the individual's traits and the situation they are in [4].

Factors connected with the working environment which are related to satisfaction with work include intellectually stimulating and demanding work, higher salaries, flexible working hours, and support of the employer. Results of studies carried out so far indicate that there is a statistically significant positive relationship between income and education, satisfaction with family life and satisfaction with work [5]. Moreover, research shows relationships between the level of satisfaction with work and social and demographic factors such as marital status, age, or area of residence. The structure of the self (a high self-esteem is connected with satisfaction with work), family life of the individual, and the social status are other factors that significantly impact satisfaction with work [4]. Despite the difficulties connected with working and performing the role of a mother, being able to function in these roles successfully may have a positive influence on the mothers' mental wellbeing. It is true even when the burdens of everyday life - such as caring for children have significantly increased [6]. 
The research, the aim of which has been to describe functioning at work in the case of single and married mothers, and to determine if the declared level of satisfaction with work differentiates types of behavior and experiences at work as well as stress coping strategies in these groups has shown that interaction of satisfaction with work and type of mothers significantly differentiated only one stress coping strategy: one of resignation. This strategy was more frequently applied by single mothers whose satisfaction with work was lower; there was a significant difference between them and the single and married mothers with a higher level of satisfaction with work, regardless of their satisfaction with work [7]. The quality and the amount of support needed by single mothers to satisfyingly combine work and the role of mother in the light of research and scientific observation is still to be determined.

\section{Social support}

The problem of social support has been present in numerous publications in recent years; it has also been the subject of research connected with human resources [8-11]. Despite that fact, one can observe a considerable demand to verify the proposed hypotheses, especially in relation to the reality in which single mothers function. For single mothers the experienced financial, work, and family problems are the significant source of stress [5], due to being unable to share these challenges with a spouse.

Elements of the environment in which an individual lives, such as availability of family members and other people able to provide support and assistance $[12,13]$ are called social resources. They are treated as help that is available for the individual in difficult situations, and they facilitate satisfaction of the individual's needs by significant people in their life $[9,14]$. In the case of single motherhood, it is particularly important as working single mothers identify single parenthood, financial problems, changes in work or in family, and problems with children as sources of stress [5].

Sęk and Cieślak [10] define social support as a type of interaction that is undertaken by one or both participants of the problematic, difficult, stressful, or critical situation. Another definition describes it as the objectively existing and available social networks; the difference between these networks and others is that through the existence of relationships, social contacts, and the sense of belonging to these networks are helpful to individuals who have found themselves in challenging circumstances. The basic core of support comes from subjective interactions necessary to activate the partners' own efforts to maintain health and growth [15].

Support may be considered from a structural or functional perspective. In the structural approach, the objective and quantitative parameters are examined; they include the size of the social network, its density, coherence, and availability. Analyzing the objective features of support, researchers pay attention to its sources (such as family, friends, working environment) [16]. Depending on the specific difficulties an individual is struggling with, support from different sources might bring different results. In the case of emotional issues caused by a loss, family members and professional therapists are especially successful in providing support [10]. Work-related stress can be alleviated by the superiors [11] as well as co-workers [17].

The functional approach analyzes the quality of the social interactions that occur in difficult situations. Based on the content of social interaction, support is usually divided into the following types: emotional, informational, instrumental, and material [10]. Emotional support is displayed as closeness, empathy, trust, care, and compassion [15,18]; instrumental support takes the form of lending others one's time, money, material resources, or services [11]. Informational support is based on assigning meaningfulness to actions; its purpose is understanding the meaning of stressful experiences [10]. Another measure of social support is the demand for support in a stressful situation [18], which impacts stress management: low demand facilitates creating new strategies to cope with difficulties [19]. Seeking support is the frequency or the scope of search for assistance from others. Protective support is understood as a way to guard one's loved ones from receiving negative information [18].

The perceived support is differentiated from the one that has actually been received. The first type of support has a prospective character while the second is retrospective and stable. Expectation to receive support in the future is a personality trait, and the support experienced in the past is a variable based on objective facts [10]. The influence of social support on individuals is explained among others by the phenomenon known as "main effect" which functions as direct protection from stressors or as a modification of the process of perceiving stressful situations. It is further explained indirectly, treating it as a buffer for the negative effects of stressful experiences [20].

Support determines the behavior of an individual by affecting the cognitive assessment of experiences 
in a stressful situation and influences the process of coping with difficulties in family life. Individuals who possess more resources are less likely to interpret their experiences as difficult and they cope more efficiently in situations that they perceive as problematic and stressful [13]. In the context of work, interpersonal relationships may be a source of stress, but its consequences may be buffered if social support is available. Contacts with others, friendships, and emotional closeness are strong predictors that are positively related with satisfaction with work [21].

It is important to remember that social support contributes to the growth of the personal resources used for accomplishing tasks in one's life, thus enhancing the individual's positive attitude towards others [22]. In the context of work, interpersonal relationships may become a source of stress; the availability of social support, however, may lessen their negative effects. Contacts with other people, friendships and emotional closeness weaken the impact of stress and function as strong predictors positively connected with satisfaction with work [21].

From the perspective of the influence it has on mothers' satisfaction with work and life and on decreasing the work-family conflict, family support might be less significant than the one received from the workplace. The research confirms the importance of social support for the employee's family offered by the employer. Among different sources of support, the one received from co-workers is important and it decreases the negative influence of work on family life [3]. According to the social cognitive theory, support has impact on the behavior connected with realization of an individual's goals, including the ones related to their work; support is also connected with an individual's efficiency at work [23].

If we interpret single motherhood as a difficult situation and a source of stress, it must be emphasized that effectiveness of the stress-coping mechanism depends on many factors, one of which is social support [24]. Life in a relationship is considered an objective indicator of the received support [10]. It has been observed that if the closest relatives, including spouses, offer more assistance in domestic work and childcare, then meeting professional obligations is not a difficult challenge for working mothers. It suggests that the spouse's support (especially emotional support) plays an important role in reducing the work-family conflict. The results of some other studies, however, contradict the above observations by showing that there is no relation between the spouse's support and the work-family conflict in the case of mothers [25].

Combining professional and family life is a source of many difficulties to single mothers. They are solely responsible for the activities and decisions which, in two-parent families, are usually shared between the parents. It is for this reason that single mothers need more support from other people. Emotional, instrumental or financial support offered by friends and close relatives is a factor connected with a decrease in the level of stress [24]. Single mothers, who face the challenge of reconciling professional and family life and who lack the support of a spouse, more often seek assistance from their relatives. The research shows that a single mother's family receives more help and support from the grandparents than its two-parent equivalent [26].

The scope and the size of that support constitute the subject of discussion. These resources may facilitate single mothers' functioning in professional roles [6], contributing to the increase of satisfaction with work [5]. Despite the significant positive effects support and assistance of one's friends and relatives has on functioning of family - which applies both to two-parent and single-mother families - this issue is not systematically analyzed and remains neglected as a subject of research. Every fifth Polish family is a single-parent unit; in most cases, the single parent is the mother - this is the reason for an urgent need to study this phenomenon. With consideration of the complexity of many issues, an attempt was made to verify the importance of social support experienced in a group of mothers and its differentiation due to the women's family situation for their satisfaction with work.

The purpose of the study has been to determine to what degree social support is differentiated by family situation, with consideration of single motherhood as a difficult circumstance, and to establish if social support is significant for satisfaction with work in the studied group of mothers. The theoretical basis for the study is the concept of resources, which supports the assumption that social support experienced by mothers will be differentiated by their family circumstances, and will be connected with their level of satisfaction with work. It is expected that there will be a relationship between social support with satisfaction with work among mothers, differentiated by the situation in the family, and it is suspected that the strength of the relationship between social support and satisfaction with work for single mothers will be significantly higher in comparison with mothers in relationships. Furthermore, the 
experienced amount of support will be differentiated by their situation in the family and the professional life.

The following hypotheses have been formulated:

1. Single mothers receive a significantly higher support from their relatives than mothers in relationships. The latter more frequently receive support from the spouse.

2. There is a significant connection between social support and satisfaction with work in the case of mothers, regardless of the family structure. The strength of that connection is stronger for single mothers than for mothers in relationships.

3. Social support is significantly higher for women who declare a higher level of satisfaction with work, regardless of their family status.

\section{MATERIAL AND METHODS}

This study used the Scale of Satisfaction with Work (SSP), designed by Zalewska [2], that is used for measuring the degree to which people feel satisfied with their work. The scale consists of 5 statements (e.g., "my working conditions are excellent," "I am happy with my job"), which are assessed on a 7-item scale. The overall result is calculated by summing up all answers, which indicates the degree of an individual's satisfaction with work. The scope of results is 5-35 pts and the higher the number, the higher is the level of satisfaction with work of the participant. Cronbach's a for SSP is 0.875 .

The Berlin Social Support Scale (BSSS), designed by Schwarzer and Schulz and adapted to Polish conditions by Łuszczyńska, Kowalska, Mazurkiewicz, and Schwarzer [27] was used for measuring social support.
The questionnaire consists of 5 independent scales that measure the cognitive and behavioral dimensions of social support, such as the following:

perceived available support: the assessment of availability of support from others,

demand for support: the degree to which an individual values social support in stressful situations,

seeking support: measure of how frequently or to what degree an individual seeks support from other people,

currently received support: the perceived help offered by others; it reduces the perceived danger in stressful situations,

buffering-protective support: it is defined as protecting others and withholding negative information.

The participants of the study declared that they exhibited behavior characteristic of this type of support towards people who were important to them which meant that the support the respondents assessed was the one they offered to others, and that they protected other people from the problems they face (Table 1).

The participants declare their attitudes towards the statements in the questionnaire on a 4 -item scale (from 1 - "definitely not" to 4 - "definitely yes"). The results are calculated for individual scales. A bigger number of points means bigger perceived social support. Cronbach's a was between $0.42-0.89$ and was similar to those obtained by the authors of the scales [27]. A personal survey designed specifically to describe the demographic properties of the studied sample was also used; it contained questions about age, education, residence, number of children, marital status, work tenure, and material situation.

Table 1. Cronbach's a for particular Berlin Social Support Scales (BSSS) [27]

\begin{tabular}{|c|c|c|}
\hline Dimensions of social support & Examples of statements & Cronbach's a \\
\hline \multicolumn{3}{|l|}{ Perceived available support } \\
\hline emotional $(\mathrm{N}=4)$ & "There is always someone who comforts me when I need it" & 0.822 \\
\hline instrumental $(\mathrm{N}=4)$ & “There are people who offer me help when I need it" & 0.436 \\
\hline Demand for support $(\mathrm{N}=4)$ & "Before making important decisions I always seek someone else's advice" & 0.418 \\
\hline Seeking support $(\mathrm{N}=5)$ & "If I don't know how to handle an issue, I ask other what they would do" & 0.832 \\
\hline \multicolumn{3}{|l|}{ Currently received support } \\
\hline emotional $(\mathrm{N}=9)$ & "That person comforted me when I felt upset" & 0.812 \\
\hline instrumental $(\mathrm{N}=3)$ & "That person was there for me when I needed them" & 0.771 \\
\hline information $(\mathrm{N}=2)$ & "That person helped me find something positive in my situation" & 0.801 \\
\hline Satisfaction with support $(\mathrm{N}=1)$ & "Overall, I am happy with that person's behavior" & - \\
\hline Buffering-protective support $(\mathrm{N}=6)$ & "I hid from him/her all bad news" & 0.860 \\
\hline
\end{tabular}




\section{Studied sample}

The study was based on a purposive sample of single mothers and mothers in relationships who acted as the control group. The sample consisted of 421 mothers, out of which 206 (49\%) had partners or were married; the remaining 215 respondents were single mothers. On average, the period of single motherhood lasted over 5 years $(\mathrm{SD}=4.37)$, in the range $1-23$ years. The average age of the participants was 36.29 (SD = 7.48). The youngest respondent was 20, and the oldest - 57 years old. Approximately $65 \%(\mathrm{~N}=271)$ of participants lived in the countryside, and the remaining 150 in the city. All participants were employed. The average time the respondents had spent working was 12.44 years ( $\mathrm{SD}=7.58,1-33$ years). Almost a half of the women participating in the study ( $\mathrm{N}=204,49 \%)$ had tertiary education, and the remaining part had secondary $(\mathrm{N}=150,36 \%)$, vocational and primary $(\mathrm{N}=67,15 \%)$ education. The participants were employed and had at least 1 child of school age. The majority $(\mathrm{N}=202,48 \%)$ had 1 or 2 children $(\mathrm{N}=179$, $43 \%)$, and the remaining part had $3-5$ children $(\mathrm{N}=40$, $9 \%)$. The respondents declared that on average, they spent around $6 \mathrm{~h} /$ day with their children $(\mathrm{SD}=4.09$ ).

The research was conducted from March to September, 2016, in the Silesian, Łódzkie, Pomeranian, KuyavianPomeranian, Mazovian, and Warmian-Masurian voivodeships.

\section{RESULTS}

The Student's t-test was used for analyzing the obtained data; the variables without homogeneity of variance were analyzed with the nonparametric Mann-Whitney $\mathrm{U}$ test. The relationship between social support and satisfaction with work was verified using Spearman's rank correlation test, as the analyzed variables did not have normal distribution.

\section{Social support for mothers}

\section{by family circumstances}

The observed differences for the experienced social support in the case of mothers (by type of motherhood) are presented in the Table 2 . At the early stage of analyses it was determined if there was variation in social support among the mothers in relationships in comparison with the single mothers. The results showed that the participants differed from each other in the following aspects of support: available instrumental support $(\mathrm{z}=-3.11, \mathrm{p}=0.002)$, demand for support $(\mathrm{t}=-2.82$, $\mathrm{p}=0.005)$, the received emotional support $(\mathrm{z}=-2.84$,

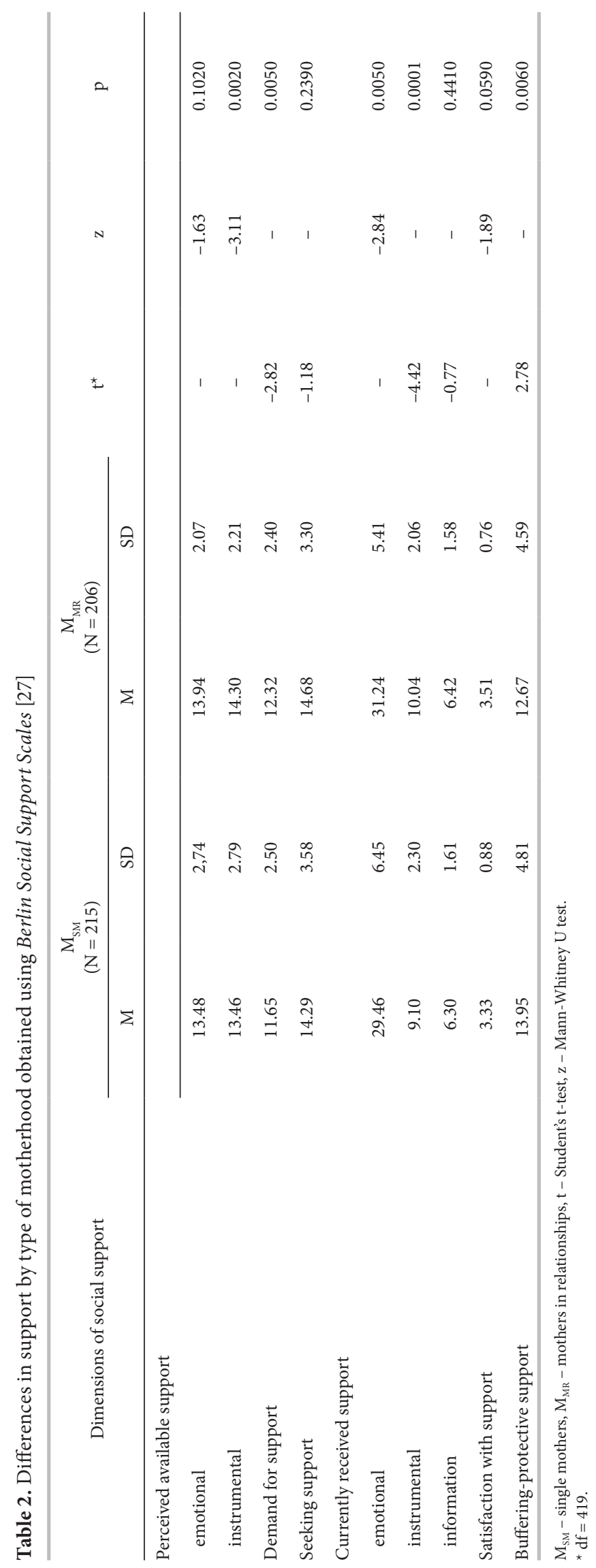


$\mathrm{p}=0.005)$ and the received instrumental support $(\mathrm{t}=-4.42, \mathrm{p}=0.0001)$, as well as the perceived protective support $(t=2.78, p=0.006)$. Single mothers had a lower perception of support in many areas, with the exception of protective support, which, in their experience, was significantly higher than in the case of mothers in relationships.

The participants of the study did not differ from each other in terms of available emotional support, seeking support, received informational support, and satisfaction with support. Single mothers significantly differed from mothers in relationships in terms of reliance on the spouse. Two thirds (66.3\%) of single mothers were never able to rely on their spouse; the same percentage of mothers in relationships declared they could count on their husbands. The results concerning reliance on friends (of both genders) and parents were similar in both groups. The respondents usually declared that they could never rely on their male friends, but they often had access to help by female friends and could always count on their parents. Single mothers could never rely on support from their parents-in-law (60\%), while the results obtained from mothers in relationships varied in this area, with only $24.5 \%$ of them always able to rely on the parents-in-law. Both groups of mothers gave similar responses to the questions about support from other relatives and colleagues, declaring that they usually did not receive help from them.

\section{Social support and satisfaction with work in mothers}

For mothers in relationships the received informational support does not reveal a statistically significant correlation with satisfaction with work. In this group, the strongest correlation was observed between instrumental support and satisfaction with work ( $r h o=0.3$, $\mathrm{p}<0.001$ ). It suggests that both the perceived and the received support (with the exception of informational support and satisfaction with support) will result in increased satisfaction with work. A surprising result in this group is the positive value of the strength of the relationship between seeking support and satisfaction with work, which has not been observed among single mothers. The results are presented in the Table 3.

Both for single mothers and those in relationships, positive, statistically significant values of coefficients of correlation have been observed between almost each type of social support with the general result for satisfaction with work; the demand for support and protective support as well as seeking support in single

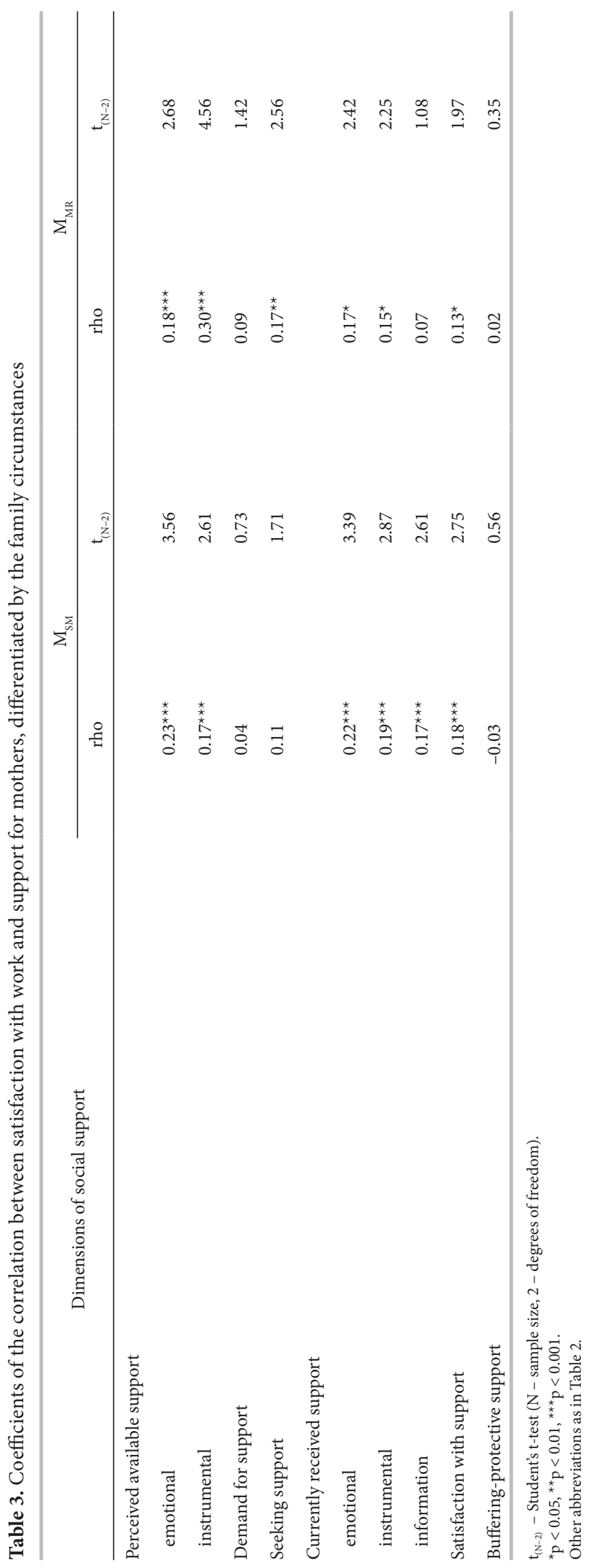


mothers have been exceptions. Among single mothers, protective support reveals a negative and statistically insignificant relationship with satisfaction with work; in this group, seeking support is not connected with satisfaction with work, contrary to the results obtained from the group of mothers in relationships.

\section{Role of social support and its role in differentiating satisfaction with work among mothers}

In order to verify the 3rd hypothesis, that has assumed that satisfaction with work is significantly differentiated by the level of social support regardless of the family status among mothers, the participants of the study were classified based on the results obtained in SSP. As the participants did not statistically differ with regard to satisfaction with work (single mothers $=21.63$, $\mathrm{SD}=7.35$, mothers in relationships $=22.01, \mathrm{SD}=6.89$, $\mathrm{t}=0.654, \mathrm{p}=0.513$ ), the division was performed for the whole group.

Table 4. Mothers differentiated by the level of satisfaction with work

\begin{tabular}{lcc}
\hline \multirow{2}{*}{ Satisfaction with work } & \multicolumn{3}{c}{ Mothers } \\
\cline { 2 - 3 } & $\mathrm{N}=421)$ \\
\hline Low (<18 pts) & 130 & $\%$ \\
Average (19-25 pts) & 159 & 30.88 \\
High (> 26 pts) & 132 & 37.77 \\
\hline
\end{tabular}

The results of the distribution of numbers for different groups are presented in the Table 4 .

A significantly higher level of social support in all its dimensions was observed in the participants of the study, with the exception of buffering-protective support, when a higher satisfaction with work was noted (Table 5).

\section{DISCUSSION}

The aim of the study has been to determine to what degree social support experienced by mothers is differentiated by their family circumstances and if the support available to mothers is a resource that has impact on their satisfaction with work, while considering single motherhood as a difficult circumstance.

The obtained results are surprising. It was expected that single mothers received considerably higher support than mothers in two-parent families. The results show, however, that the situation is ambiguous. In com-

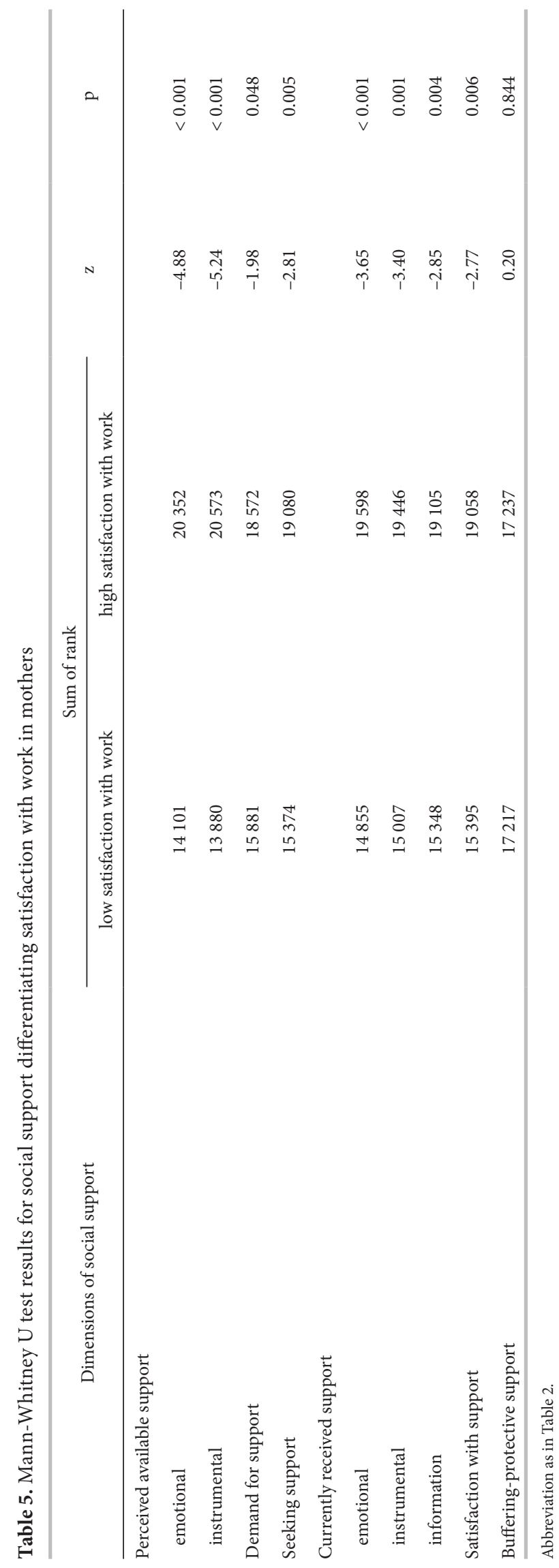


parison with mothers in two-parent families, single mothers perceive the support they receive as lower and less satisfying, both in terms of perceived instrumental support (the result needs to be interpreted with caution, as the coefficient $a$ for the subscale Perceived Available Social Support is low) as well as received emotional and instrumental support. At the same time, however, single mothers declare a lower demand for support (the result needs to be interpreted with caution, as the coefficient a for the subscale Demand for Support is low). They feel they have to rely on themselves more and remain forced to cope with their problems on their own, which requires an increased readiness to create new strategies in stressful situations, and makes it necessary to expand the coping-related skills or to learn new ones [28]. It appears, then, that single mothers have a bigger sense of self-reliance, feel obliged to maintain this trait, and want to be perceived as such to a bigger extent than mothers in relationships. This, perhaps, is their attempt to preserve their sense of control over their life [29]. It is, however, accompanied by a lower satisfaction with the received support, which suggests that, due to mistaken assumptions about their situation, the support they are offered is misguided. It is known that single mothers ask for support as frequently and in similar matters as mothers in relationships. Their expectations of support, however, are probably not fulfilled to a satisfying degree. This causes the lower level of satisfaction with support and lower willingness to rely on others, followed by a focus on self-reliance [30]. Single motherhood is connected with the conviction that one has to count on oneself. It is difficult to assess the influence of earlier interpersonal experiences on this attitude, although it is known that single motherhood is usually a result of failure of the relationship with the child's father, as single mothers are mainly divorced and unmarried women who have been abandoned by their partners despite the shared parenthood. These are painful experiences which may result in unwillingness to start new relationships and cause caution in showing trust.

The result that indicates that single mothers offer protective support more than mothers in relationships is also interesting. This type of support amounts to mothers protecting their relatives from receiving negative information [18]. It suggests that single mothers want to protect their family members from negative information. It is, perhaps, caused by single mothers' higher sensitivity to criticism, stereotypes, and negative information. Being protected from negative infor- mation might make it more difficult for the relatives to realistically assess the situation of the protecting person, and thus lead to inadequate behavior; this in turn might create the situation in which a single mother receives less support and understanding from her family [31]. As this study suggests, in this way, the protection might become an indirect obstacle to satisfaction with work. The results of this study do not reveal significant connections in this area, but, contrary to the expected findings, the obtained results indicate that it is necessary to explore this issue further. Higher protective support coming from a single mother reveals that mothers in relationships apply this type of protection less frequently. It is, perhaps, the consequence of these mothers being less vulnerable to distress caused by negative information, as most of them can rely on their spouse's support, which has also been confirmed by research [28]. Some women in relationships, however, cope with negative information on their own, which also reveals the hardships they face.

The research to date indicates that working women who are willing to seek help and support are more satisfied with their work, which is, to them, more subjectively important [7]. The obtained results confirm that observation also in reference to working women whose family situation is varied, as both bigger available and received support, and a bigger level of satisfaction with support is connected with generally higher satisfaction with work in that group. It is especially important to mothers who raise their children on their own, but it does have significance in both groups. Assuming, afterwards [13], that social support is a resource, having a partner will be a source of it. Therefore, lack of a spouse will, for single mothers, mean having access to one resource fewer than in the case of married mothers who are in a more favorable situation. Social support as a resource is thus a factor promoting sense of satisfaction with work, regardless of an individual's family situation, which is consistent with data from other studies presented in literature [21].

Support perceived as available as well as support that is actually received, and the sense that it is on a satisfying level is positively and strongly connected with satisfaction with work, in particular among single mothers. Their difficult situation, caused by the necessity to reconcile many duties and by the individual responsibility justifies the value of potentially available and appropriate help in many aspects of functioning [28]. Seeking help and the conviction that it will be offered when needed impacts sense of satisfaction with 
work, but only in the case of mothers in relationships. Single mothers less frequently seek support, instead counting on their own resources and independence in coping with the professional and family obligations. At the same time, the support that they do receive, and that they see as available, is, to them, a great source of strength. Perhaps the additional interpersonal activity required to develop the pool of support is an effort single mothers cannot afford, as they need to spend energy on numerous other duties; in this situation, the already established and verified relationships may be a source of support and help to obtain which one does not have to expend any additional effort.

According to the expectations, the results showed that satisfaction with work was significantly differentiated by the level of social support, regardless of family status. These results suggest that a high level of satisfaction with work in the studied sample is accompanied by all types of social support, except for the protective support. Perhaps their resilience to difficult situations at work is higher due to the support they receive from their husbands (in the case of mothers in relationships) or their friends or parents (single mothers).

Other research has shown that lower satisfaction with relationships with others and experiencing unsatisfying interactions creates a tendency to enter conflicts and difficulties when co-operation is necessary, and eventually an overall lowered resilience to social stressors in the workplace [4]. Both available and received emotional, instrumental, and informational support, and the level of satisfaction with the obtained support are particularly important for a higher satisfaction with work. It is an important resource for a working woman and it allows her to experience satisfaction with work, which in turn also increases the resources she has at her disposal. Increasing social resources may contribute to an increase in satisfaction with work in every mother; it is, however, particularly true for single mothers, as it stabilizes the situation of the whole family, which benefits from the effects from the mother's work. It also contributes to the woman's well-being and a sense of fulfillment, which in turn multiplies the resources of the whole family [2]. Other research has established that the duties connected with the role of mother are positively connected with satisfaction with work [32]. This shows that all support - not only one offered by the relatives - which helps to increase functionality of the family may have an indirect relationship with the experienced satisfaction with work in the case of mothers.
It has previously been established that frequent contacts with others, friendship, and emotional support are strongly connected with satisfaction with work [21]. The presented results confirm these reports.

To conclude, it has to be emphasized that due to the nature of their circumstances, single mothers value different aspects of social support from those that mothers in relationships, and their significance for satisfaction with work is bigger. Almost all types of support, especially available and received emotional support, correlate with satisfaction with work in the case of single mothers. The study has also managed to observe an unexpected effect of protective support which, in this case, does not have a significant role; it might indicate that satisfaction with work is not dependent on the degree of protection against negative information. The efforts the relatives might undertake to provide this kind of protection do not have much significance; these efforts could be directed towards other aspects of support which are shown to be more important.

\section{CONCLUSIONS}

The results show that mothers who were more satisfied with work declared having more support (both perceived and received) from their environment than those less satisfied. This regularity is more often found among single mothers than mothers in relationships for whom the received informational support does not bear on their satisfaction with work. In general, the study shows that social support is differentiated both by the situation in the family and at work, and has a different importance for single from that for married mothers. Moreover, the results allow us to draw the conclusion that all studied types of support, except for protective support, were significant for high satisfaction with work in the case of mothers, regardless of their family status.

\section{Limitations and implications of the study}

Even though the study was conducted on a large group of single mothers, the reasons for their single mother status was not analyzed in detail. Single motherhood might be a consequence of a series of difficult experiences which might distort perception of support and prevent an individual from accepting it. These and other determinants of perception of the available and the received support were not controlled, and according to the subjective assessment by the participants of the study, they might have influence on the final result. 
The study has shown that satisfaction with work correlates with social support, and the main criterion for selection of the sample has been the family status. In this way, other important psychosocial factors (such as unequal salaries, demand for work, responsibility, etc.) have been disregarded. For this reason the best sample for this type of study would be employees of one company or individuals selected from the same occupational group; this would increase likelihood of similar working conditions and a broader perspective for generalization of the results.

Nevertheless, the study has confirmed the conclusions about support as a social resource for single mothers and its differentiating significance to satisfaction with work. The results allow to emphasize the weight of interaction with family members, friends, and colleagues which might not be fully utilized as available sources of support. At the same time, the issue of appropriateness of support arises, and of necessity of directing it where it is actually needed, which suggests that social sensitivity in that area needs to be deepened. The results also confirm the existence of a tendency among single mothers to shield their relatives from negative information. As the study indicates, it is only an illusion of support as it has a significantly less supportive role; what is more, it exacerbates the hardships of single motherhood.

\section{Suggestions for future research}

The need still remains for research into the role of the social and personal resources of single mothers in coping with difficulties. Future research should include further analysis of variables in different subgroups of single mothers. Moreover, the observed results show that high level of social support which facilitates an increase of satisfaction with work is still experienced by mothers as low; this suggests that further exploration of this issue is needed.

\section{REFERENCES}

1. Bańka A. [Satisfaction with work and motivation]. In: Strelau J, editor. [Psychology. Academic handbook]. Vol. 3. Warszawa: Gdańskie Wydawnictwo Psychologiczne; 2000, p. 329-33. Polish.

2. Zalewska AM. [The satisfaction with job scale - A measure of cognitive aspect of overall job satisfaction]. Acta Univ Lodz Folia Psychol. 2003;7:49-61. Polish.

3. Bajcar B, Borkowska A, Czerw A, Gąsiorowska A. [Satisfaction with work in professions with a social mission].
Gdańsk: Gdańskie Wydawnictwo Psychologiczne; 2011. Polish.

4. Wołowska A. [Satisfaction with work and its determinants and a sense of quality of life among public administration officials]. Rocz Andrag. 2013;20:119-32, https://doi. org/10.12775/RA.2013.006. German.

5. Robbins LR, McFadden JR. Single mothers: The impact of work on home and the impact of home on work. J Fam Consum Sci Educ [Internet]. 2003[cited 2017 May 30];21(1): 1-10. Available from: http://www.natefacs.org/Pages/v21 no1/v21no1Robbins.pdf.

6. Ciabattari T. Single mothers, social capital, and work-family conflict. J Fam Issues. 2007;28(1):34-60, https://doi. org/10.1177/0192513X06292809.

7. Napora E, Andruszkiewicz A, Basińska MA. Types of work-related behavior and experiences and stress coping strategies among single mothers. Differentiating role of work satisfaction. Int J Occup Med Environ Health. 2018; 31(1):55-69, https://doi.org/10.13075/ijomeh.1896.01052.

8. Juczyński Z, Ogińska-Bulik N, editors. [Social and personal resources beneficial to the health of individuals]. Łódź: Wydawnictwo Uniwersytetu Łódzkiego; 2003. Polish.

9. Sęk H. [Social support as a category of resources and complex functions of support]. In: Juczyński Z, Ogińska-Bulik N, editors. [Personal and social resources conducive to the health of individuals]. Łódź: Wydawnictwo Uniwersytetu Łódzkiego; 2003. p. 17-32. Polish.

10. Sęk H, Cieślak R. [Social support: Ways of defining, types, and sources of support. Selected theoretical concepts]. In: Sęk H, Cieślak R, editors. [Social support, stress and health]. Warszawa: Polskie Wydawnictwo Naukowe; 2004. p. 11-28. Polish.

11. Namayandeh H, Yaacob SN, Juhari R. The influences of work support and family support on work-family conflict (W-FC) among married female nurses in Shiraz-Iran. J Am Science. 2010;6(12):534-40.

12. Basińska MA. [Psychological functioning of patients with selected endocrinological diseases]. Bydgoszcz: Wydawnictwo Uniwersytetu Kazimierza Wielkiego; 2009. Polish.

13. Hobfoll S. [Stress, culture, and community. Psychology and the philosophy of stress]. Gdańsk: Gdańskie Wydawnictwo Psychologiczne; 2006. Polish.

14. Abramson DM, Grattan LM, Mayer B, Colten CE, Arosemena FA, Bedimo-Rung A, et al. The resilience activation framework: A conceptual model of how access to social resources promotes adaptation and rapid recovery in post-disaster settings. J Behav Health Serv Res. 2015;1:42-57, https://doi.org/10.1007/s11414-014-9410-2.

15. Dołega Z. [The relationship of social support and loneliness in adolescence]. In: Kwiecińska R, Szymański MJ, editors. 
[Teenagers and adults. Tensions between socialization and education]. Kraków: Wydawnictwo Akademii Pedagogicznej im. KEN w Krakowie; 2001. p. 549-50. Polish.

16. Halbesleben JRB. Sources of social support and burnout: A meta-analytic test of the conservation of resources model. J Appl Psychol. 2006;91:1134-45, https://doi.org/ 10.1037/0021-9010.91.5.1134.

17. Burke RJ, Greenglass E. Work stress, role conflict, social support, and psychological burnout among teachers. Psychol Rep. 1993;73(2):371-80, https://doi.org/10.2466/pr0. 1993.73.2.371.

18. Schulz U, Schwarzer R. Social support in coping with illness: The Berlin Social Support Scales (BSSS). Diagnostica 2003;49:73-82, https://doi.org/10.1026/0012-1924.49.2.73.

19. Cepuch G, Krupa A, Wojtas K. [Stress management and social support of parents of children with life-threatening diseases]. Onkol Pol. 2011;14(4):174-81. Polish.

20. Smoktunowicz E, Cieślak R, Żukowska K. [The role of social support in the context of organizational stress and commitment to work]. Stud Psychol. 2013;51(4):25-37. Polish.

21. Morgeson FP. Social relationships matter in job satisfaction. J Appl Psychol. 2007;91(6):1321-39, https://doi.org/ 10.1037/0021-9010.91.6.1321.

22. Brummelhuis LL, Bakker AB. A resource perspective on the work-home interface: The work-home resource model. Am Psychol. 2012;67(7):545-56, https://doi.org/10.1037/ a0027974.

23. Bandura A. Social cognitive theory: An agentic perspective. Annu Rev Psychol [Internet]. 2001[cited 2017 Mar 21]; 52:1-26. Available from: https://www.uky.edu/ eushe2/ Bandura/ Bandura2001ARPr.pdf.

24. Heszen I. [Psychology of stress]. Warszawa: Wydawnictwo Naukowe PWN; 2013. Polish.

25. Aryee S, Luk V, Leung A, Lo S. Role stressors, interrole conflict, and well-being: The moderating influence of spousal support and coping behaviors among employed parents in Hong Kong. J Vocat Behav. 1999;54(2):259-78, https:// doi.org/10.1006/jvbe.1998.1667.

26. Scott EK, Hurst A, London AS. Out of their hands: Patching together care for children when parents move from welfare to work [Internet]. New York: MDRC; 2003 [cited 2017 Jun 20]. Available from: https://www.mdrc.org/publication/out-their-hands/file-full.

27. Łuszczyńska A, Kowalska M, Mazurkiewicz M, Schwarzer R. [The Berlin Social Support Scales (BSSS): Results of preliminary studies on the adaptation of the scales and their psychometric properties]. Stud Psychol. 2006; 44(3):17-27. Polish

28. Iskra J. [The impact of personal resilience on one's selfimage. Research on students]. In: Golińska L. BielawskaBatorowicz E, editors. [Family and work in conditions of crisis]. Łódź: Wydawnictwo Uniwersytetu Łódzkiego; 2011. p. 525-39. Polish.

29. Oleś P, Drat-Ruszczak K. [Personality]. In: Strelau J, Doliński D, editors. [Psychology. Academic handbook]. Vol. 1. Gdańsk: Gdańskie Wydawnictwo Psychologiczne; 2008. p. 651-764. Polish.

30. Semmer N. Personality, stress and coping. In: Vollrath M, editor. Handbook of personality and health. Chichester: Wiley; 2006, https://doi.org/10.1002/9780470713860.ch4.

31. Satir V. [Family therapy: Theory and research]. Gdańsk: Gdańskie Wydawnictwo Psychologiczne; 2000. Polish.

32. Kurpiel D, Walęcka-Matyja K. [Professional activity, children upbringing styles, and stress coping strategies in mothers of hemiplegic adolescents and mothers of healthy children]. In: Janicka I, Znajmiecka-Sikora M, editors. [Family and career. Equalbalance or role conflict?]. Łódź: Wydawnictwo Uniwersytetu Łódzkiego; 2014. p. 105-28. Polish.

This work is available in Open Access model and licensed under a Creative Commons Attribution-NonCommercial 3.0 Poland License - http://creativecommons.org/licenses/by-nc/3.0/pl/deed.en. 